\title{
Glutathione S-transferase omega genes in Alzheimer and Parkinson disease risk, age-at- diagnosis and brain gene expression: an association study with mechanistic implications
}

Mariet Allen ${ }^{1}$, Fanggeng Zou' ${ }^{1}$, High Seng Chai ${ }^{2}$, Curtis S Younkin', Richard Miles ${ }^{1}$, Asha A Nair ${ }^{2}$, Julia E Crook ${ }^{3}$, V Shane Pankratz², Minerva M Carrasquillo', Christopher N Rowley ${ }^{1}$, Thuy Nguyen', Li Ma', Kimberly G Malphrus', Gina Bisceglio', Alexandra I Ortolaza', Ryan Palusak', Sumit Middha², Sooraj Maharjan², Constantin Georgescu', Debra Schultz ${ }^{4}$, Fariborz Rakhshann ${ }^{4}$, Christopher P Kolbert ${ }^{4}$, Jin Jen ${ }^{4}$, Sigrid B Sando ${ }^{5,6}$, Jan O Aasly ${ }^{5,6}$,

Maria Barcikowska ${ }^{7}$, Ryan J Uitti ${ }^{8}$, Zbigniew K Wszolek ${ }^{8}$, Owen A Ross ${ }^{1}$, Ronald C Petersen ${ }^{9}$, Neill R Graff-Radford ${ }^{8}$, Dennis W Dickson', Steven G Younkin ${ }^{1}$ and Nilüfer Ertekin-Taner ${ }^{1,8^{*}}$

\begin{abstract}
Background: Glutathione S-transferase omega-1 and 2 genes (GSTO1, GSTO2), residing within an Alzheimer and Parkinson disease (AD and PD) linkage region, have diverse functions including mitigation of oxidative stress and may underlie the pathophysiology of both diseases. GSTO polymorphisms were previously reported to associate with risk and age-at-onset of these diseases, although inconsistent follow-up study designs make interpretation of results difficult. We assessed two previously reported SNPs, GSTO1 rs4925 and GSTO2 rs156697, in AD (3,493 ADs vs. 4,617 controls) and PD (678 PDs vs. 712 controls) for association with disease risk (case-controls), age-at-diagnosis (cases) and brain gene expression levels (autopsied subjects).

Results: We found that rs156697 minor allele associates with significantly increased risk (odds ratio $=1.14, p=$ 0.038 ) in the older ADs with age-at-diagnosis $>80$ years. The minor allele of GSTO1 rs4925 associates with decreased risk in familial PD (odds ratio $=0.78, p=0.034$ ). There was no other association with disease risk or ageat-diagnosis. The minor alleles of both GSTO SNPs associate with lower brain levels of GSTO2 $\left(p=4.7 \times 10^{-11}-1.9 \times\right.$ $\left.10^{-27}\right)$, but not GSTO1. Pathway analysis of significant genes in our brain expression GWAS, identified significant enrichment for glutathione metabolism genes $(p=0.003)$.
\end{abstract}

Conclusion: These results suggest that GSTO locus variants may lower brain GSTO2 levels and consequently confer $A D$ risk in older age. Other glutathione metabolism genes should be assessed for their effects on $A D$ and other chronic, neurologic diseases.

Keywords: GSTO genes, Disease risk, Gene expression, Association

\section{Background}

Glutathione S-Transferase (GST) family of genes have been implicated in multiple neuropsychiatric [1-4] and neurodegenerative diseases [5-11]; where altered levels or function of these enzymes is thought to impact levels

\footnotetext{
* Correspondence: Taner.Nilufer@mayo.edu

${ }^{1}$ Mayo Clinic Florida, Department of Neuroscience, Jacksonville, FL, USA Full list of author information is available at the end of the article
}

of oxidative stress and/or inflammation in a way that contributes to disease susceptibility. A linkage locus on chromosome 10q that has been implicated in both Alzheimer's (AD) [11-13] and Parkinson's disease (PD)[13] harbors two GST genes of the omega class: GSTO1 and GSTO2, which are approximately $75 \mathrm{~kb}$ apart.

GSTOs have enzymatic activities as thioltransferases and dehydroascorbate reductases that promote 
antioxidant activity and can also function in metabolism of drugs and toxins[14]. Additionally, GSTO1 was shown to promote activation of the pro-inflammatory cytokine, interleukin-1 $\beta$ (IL-1 $\beta$ ) by post-translational processing[15]. Given their location and function, they have been studied as candidate genes in $\mathrm{AD}$ and $\mathrm{PD}$ $[5,6,9,11,14,16-18]$. Li et al. compared hippocampal gene expression levels in $6 \mathrm{AD}$ vs. 2 control brains and identified significantly lower GSTO1 levels in the AD hippocampi[5]. This group studied AD and PD families that showed linkage to chromosome 10, using the age-atonset phenotype [13] and identified association of multiple SNPs at the GSTO locus with delayed age-at-onset of both diseases[5], with the strongest effects observed for GSTO1 rs4925 and GSTO2 rs2297235 SNPs that are in tight linkage disequilibrium (LD). No significant influence was detected for either $\mathrm{AD}$ or PD risk in this study.

Since this initial report, several follow-up studies have been published with mixed approaches and results. Kölsch et al. reported association of rs4925 with earlier age-at-onset of $\mathrm{AD}$, thus in opposite direction to the original report[6], and no effect on AD risk. Lee et al. found modest association of rs4925 with AD risk in Carribean-Hispanic families that show linkage to chromosome 10q[11] as did Capurso et al. in an Italian casecontrol series[9], though neither study detected an ageat-onset effect. A case-control study by Wahner et al. was the only report for an effect of GSTO locus on PD risk, with both rs4925 and rs2297235 conferring protection, especially in those with smoking history[16]. Additionally, several studies reported lack of association with age-at-onset or risk of $\mathrm{AD}[17,18]$ or $\mathrm{PD}[14]$.

Additional investigation of the GSTO locus is needed to further elucidate the role of these genetic variants in $\mathrm{AD}$ and $\mathrm{PD}$, especially given the potential to establish the glutathione metabolism as a molecular pathway that is common to multiple, chronic neurologic diseases. An important shortcoming of most prior reports on the GSTO locus is the modest sample sizes, which could underlie the inconsistent results likely due to lack of power, sample or locus heterogeneity or a combination of these factors. Both $\mathrm{AD}[19,20]$ and $\mathrm{PD}[21]$ are complex diseases with substantial genetic component. Some of the genetic risk for these diseases has been identified via linkage and association studies and shown to influence age-at-onset[19-23]. More recently, genome-wide association studies (GWAS) of AD[24-28] and PD $[29,30]$, with sample sizes exceeding 10,000 subjects provide considerably greater power for detection of susceptibility loci. Despite their advantages, GWAS do not explain all of the underlying genetic component of these and other complex diseases, thus necessitating alternative approaches[31], including analysis of quantitative phenotypes.

In this study, we assessed the GSTO locus for its role in $\mathrm{AD}$ and $\mathrm{PD}$, using an in-depth approach aimed at surmounting these challenges. Given the original report of association with delayed age-at-onset of $\mathrm{AD}$ and $\mathrm{PD}$ $[5,7]$, and with risk of AD in some follow-up studies $[9,11]$, we postulate that GSTO locus variants confer risk of LOAD in older age. We have a collection of $>8,000$ late-onset $\mathrm{AD}$ (LOAD) case-controls, which includes a large series of older subjects $\geq 80$ years of age-at-diagnosis/death (clinical/autopsied LOADs) or evaluation (controls). We analyzed two previously reported, coding SNPs in GSTO1 and GSTO2 for association both with disease risk and age-at-diagnosis in the LOAD series, as well as a large PD series. Reduced expression levels of GSTO1 [5] and other glutathione metabolism genes $[10,32]$ have been reported in AD. We therefore analyzed the GSTO SNPs for association with brain GSTO1 and GSTO2 levels in > 750 brain samples from autopsied subjects with $\mathrm{AD}$ and other brain pathologies to determine whether they influenced disease risk by affecting brain gene expression. In an expression GWAS (eGWAS) testing association of 24,526 transcript levels measured in these brain samples with 213,528 cisSNPs within $\pm 100 \mathrm{~kb}$ of the tested transcript, we identified 686 genes that have significant cisSNP/transcript associations (in-press, PLoS Genetics). We analyzed these genes to discover molecular pathways that are enriched for genes with significant brain cisSNPs, and identified glutathione metabolism as one of the top pathways. Our results suggest that GSTO locus variants influence brain GSTO2 levels and confer AD risk at older age. These findings have mechanistic implications for the GSTO locus and glutathione metabolism genes, which should be explored further in $\mathrm{AD}$ and other chronic, neurologic diseases to identify functional variants that influence disease risk by altering brain gene expression levels.

\section{Results}

Association of GSTO locus SNPs with LOAD and PD risk GSTO locus SNPs rs156697 and rs4925 were tested for association with disease risk in an older series $(>80$ years) of 1,368 LOADs vs. 1,623 controls; in a younger series of 2,193 LOADs vs. 3,060 controls (60-80 years) and in 678 PDs vs. 712 controls (Table 1 Table 2 Table 3 and Table 4), using logistic regression analysis. GSTO2 rs156697 was significantly associated with LOAD in the older series $(p=0.038)$, with the minor allele conferring increased risk $(\mathrm{OR}=1.14,95 \%$ confidence interval = $95 \% \mathrm{CI}=1.01-1.30)$ (Table 5$)$. There was no other significant disease risk association in the combined younger LOAD series (Table 6) or LOAD series of all ages 
Table 1 LOAD case-control series demographics: LOAD series over age 80

\begin{tabular}{cccccc}
\hline Diagnosis & Series & $\mathbf{N}$ & $\begin{array}{c}\text { Mean Age } \\
\text { (range) }\end{array}$ & Males (\%) & ApoE4+ (\%) \\
\hline & ALL & 1,368 & $84(80-105)$ & $437(32)$ & $722(53)$ \\
\hline & JS & 315 & $84(80-95)$ & $114(36)$ & $171(54)$ \\
\hline RS & 306 & $86(80-104)$ & $113(37)$ & $127(42)$ \\
\hline AD cases & AUT & 314 & $87(80-105)$ & $100(32)$ & $193(61)$ \\
\hline & NCRAD & 153 & $84(80-98)$ & $45(29)$ & $93(61)$ \\
\hline PS & 101 & $83(80-90)$ & $24(24)$ & $45(45)$ \\
\hline NW & 179 & $86(80-96)$ & $41(23)$ & $93(52)$ \\
\hline ALL & 1,623 & $84(80-100)$ & $636(39)$ & $347(21)$ \\
\hline JS & 322 & $85(80-100)$ & $137(43)$ & $71(22)$ \\
\hline RS & 973 & $84(80-99)$ & $393(40)$ & $219(23)$ \\
\hline AUT & 102 & $86(80-98)$ & $49(48)$ & $16(16)$ \\
\hline NCRAD & 86 & $87(80-99)$ & $32(37)$ & $10(12)$ \\
\hline PS & 22 & $85(80-91)$ & $5(23)$ & $3(14)$ \\
\hline NW & 118 & $85(80-96)$ & $20(17)$ & $28(24)$ \\
\hline
\end{tabular}

(Table 7), although there were trends for increased LOAD risk with the minor allele of rs156697 in the LOAD series of all ages $(p=0.18, \mathrm{OR}=1.06)$ and of rs4925 in the older LOAD series $(p=0.15$, OR $=1.10)$. Analysis of the six individual LOAD series of the older age group revealed consistently increased risk estimates for rs156697 (Table 5), which is also evident from the meta-analysis (Figure 1a), where there is no evidence of between-series heterogeneity (Breslow-Day $p=0.97$ ). In contrast, the younger LOAD series is significantly heterogeneous (Breslow-Day $p=0.004$ ), with three series showing increased (JS, NW, PS) and the other three (RS,

Table 2 LOAD case-control series demographics: LOAD series ages $60-80$

\begin{tabular}{cccccc}
\hline Diagnosis & Series & $\mathbf{N}$ & $\begin{array}{c}\text { Mean Age } \\
\text { (range) }\end{array}$ & Males (\%) & ApoE4+ (\%) \\
\hline & ALL & 2,193 & $74(61-80)$ & $872(40)$ & $1,539(70)$ \\
\hline JS & 549 & $74(61-80)$ & $212(39)$ & $378(69)$ \\
\hline RS & 291 & $74(61-80)$ & $122(42)$ & $201(69)$ \\
\hline AD cases & AUT & 267 & $74(61-80)$ & $139(52)$ & $159(60)$ \\
\hline & NCRAD & 542 & $73(61-80)$ & $199(37)$ & $451(83)$ \\
\hline & PS & 378 & $75(64-80)$ & $137(36)$ & $226(60)$ \\
\hline NW & 166 & $74(61-80)$ & $63(38)$ & $124(75)$ \\
\hline & ALL & 3,060 & $73(60-80)$ & $1,404(46)$ & $776(25)$ \\
\hline JS & 650 & $73(60-80)$ & $271(42)$ & $200(31)$ \\
\hline RS & 1,433 & $75(60-80)$ & $720(50)$ & $351(24)$ \\
\hline AUT & 258 & $72(61-80)$ & $158(61)$ & $64(25)$ \\
\hline NCRAD & 122 & $72(61-80)$ & $48(39)$ & $24(20)$ \\
\hline PS & 164 & $72(64-80)$ & $38(23)$ & $33(20)$ \\
\hline NW & 433 & $73(61-80)$ & $169(39)$ & $104(24)$ \\
\hline
\end{tabular}

Table 3 LOAD case-control series demographics: LOAD series All Ages

\begin{tabular}{cccccc}
\hline Diagnosis & Series & $\mathbf{N}$ & $\begin{array}{c}\text { Mean Age } \\
\text { (range) }\end{array}$ & Males (\%) & ApoE4+ (\%) \\
\hline & ALL & 3,561 & $78(61-105)$ & $1,309(37)$ & $2,261(63)$ \\
\hline JS & 864 & $78(61-95)$ & $326(38)$ & $549(64)$ \\
\hline RS & 597 & $80(61-104)$ & $235(39)$ & $328(55)$ \\
\hline AD cases & AUT & 581 & $81(61-105)$ & $239(41)$ & $352(61)$ \\
\hline & NCRAD & 695 & $75(61-98)$ & $244(35)$ & $544(78)$ \\
\hline PS & 479 & $77(64-90)$ & $161(34)$ & $271(57)$ \\
\hline NW & 345 & $80(61-96)$ & $104(30)$ & $217(63)$ \\
\hline ALL & 4,683 & $77(60-100)$ & $2,073(44)$ & $1,122(24)$ \\
\hline JS & 972 & $77(60-100)$ & $408(42)$ & $271(28)$ \\
\hline RS & 2,406 & $78(60-99)$ & $1,113(46)$ & $570(24)$ \\
\hline AUT & 360 & $76(61-98)$ & $207(58)$ & $80(22)$ \\
\hline NCRAD & 208 & $78(61-99)$ & $80(38)$ & $34(16)$ \\
\hline PS & 186 & $73(64-91)$ & $43(23)$ & $36(19)$ \\
\hline & NW & 551 & $75(61-96)$ & $222(40)$ & $132(24)$ \\
\hline
\end{tabular}

AUT, NCRAD) with protective risk estimates (Table 6 Figure 1b).

PD series were composed of those with (PD FAM) or without (PD-SPO) family history of PD (Table 4). Assessment of these individual series revealed significant association of rs4925 with lower PD risk in the familial PD series $(p=0.034, \mathrm{OR}=0.78)$ and a trend for decreased risk with $\mathrm{rs} 156697(p=0.116$, OR $=0.83)$ in this series (Table 8). There was no association with PD risk in the sporadic PD or the combined series.

\section{Association of GSTO locus SNPs with AD and PD age-at- diagnosis}

We employed age-at-diagnosis (clinical) or death (autopsy) as the surrogate quantitative variable for ageat-onset in our LOAD subjects (3,561 LOADs), who had an age range of 61-105 (mean age $=78$, Table 1 Table 2 and Table 3). Analysis of rs156697 and rs4925 did not identify any significant association with age-at-diagnosis in the combined or individual LOAD series, although there was a trend for rs156697 for delayed age-at-diagnosis in the combined series $(p=0.098)$ (Additional File 1: Table S1). There was no significant age-at-diagnosis association when the older and younger LOADs were

Table 4 PD case-control series demographics

\begin{tabular}{lccccc}
\hline Diagnosis & Series & N & $\begin{array}{c}\text { Mean Age } \\
\text { (range) }\end{array}$ & Males (\%) & ApoE4+ (\%) \\
\hline PD (Sporadic) & & 421 & $65(25-94)$ & $150(36)$ & $121(29)$ \\
\hline PD (Familial) & PD (USA) & 257 & $62(32-89)$ & $93(36)$ & $71(28)$ \\
\hline PD (All) & 678 & $64(25-94)$ & $243(36)$ & $192(28)$ \\
\hline Control & 712 & $66(18-89)$ & $299(42)$ & $198(28)$ \\
\hline
\end{tabular}


Table 5 Association of GSTO locus SNPs with LOAD risk in the older LOAD series with ages > 80 years

\begin{tabular}{|c|c|c|c|c|c|c|c|}
\hline \multicolumn{8}{|c|}{$\mathrm{N}$ (MAF) } \\
\hline rs\# & Locus & Series & $A D$ & Control & OR & $95 \% \mathrm{Cl}$ & p-value \\
\hline & & All & $1,338(0.37)$ & $1,604(0.33)$ & 1.14 & $1.01-1.30$ & 0.038 \\
\hline & & JS & $309(0.36)$ & $319(0.34)$ & 1.09 & $0.85-1.41$ & NS \\
\hline & & RS & $299(0.37)$ & $963(0.33)$ & 1.21 & $0.98-1.48$ & 0.073 \\
\hline \multirow[t]{7}{*}{ rs156697 } & GSTO2 & AUT & $311(0.40)$ & $99(0.36)$ & 1.19 & $0.81-1.75$ & NS \\
\hline & & NCRAD & $146(0.37)$ & $86(0.30)$ & 1.29 & $0.81-2.05$ & NS \\
\hline & & NW & $176(0.33)$ & $116(0.30)$ & 1.19 & $0.81-1.76$ & NS \\
\hline & & PS & $97(0.38)$ & $21(0.33)$ & 1.38 & $0.62-3.11$ & NS \\
\hline & & All & $1,341(0.33)$ & $1,595(0.30)$ & 1.10 & $0.97-1.25$ & 0.151 \\
\hline & & JS & $306(0.31)$ & $321(0.30)$ & 1.08 & $0.23-1.41$ & NS \\
\hline & & RS & $302(0.33)$ & $960(0.30)$ & 1.17 & $0.95-1.44$ & 0.134 \\
\hline \multirow[t]{4}{*}{ rs4925 } & GSTO1 & AUT & $313(0.35)$ & $99(0.35)$ & 1.00 & $0.69-1.46$ & NS \\
\hline & & NCRAD & $149(0.34)$ & $80(0.28)$ & 1.28 & $0.80-2.05$ & NS \\
\hline & & NW & $173(0.30)$ & $114(0.28)$ & 1.13 & $0.76-1.70$ & NS \\
\hline & & PS & $98(0.35)$ & $21(0.33)$ & 1.11 & $0.48-2.58$ & NS \\
\hline
\end{tabular}

Results of multivariate logistic regression analysis are shown for each SNP, each series individually and for the combined series. $\mathrm{N}=$ number of subjects, MAF = minor allele frequency, OR = odds ratio; NS = not significant.

assessed separately (data not shown). The combined PD series had an age range of 25-94 (mean age $=64$, Table 4). There was no significant association of either GSTO SNP with PD age-at-diagnosis (Additional File 1: Table S1).

\section{Association of GSTO locus SNPs with brain gene expression}

In an eGWAS using 773 brain samples, we measured levels of 24,526 transcripts from the cerebellum and temporal cortex of autopsied subjects with and without AD pathology (in-press, PLoS Genetics). Control subjects without AD pathology often had other brain pathologies. We determined the association of rs156697 and rs4925 with brain GSTO1 and GSTO2 levels in these series, using linear regression analysis. Both SNPs had significant association with brain GSTO2 (Table 9, 10), but not with GSTO1 levels (data not shown). This association was significant for GSTO2 transcript levels measured from both the cerebellum and the temporal

Table 6 Association of GSTO locus SNPs with LOAD risk in the younger LOAD series with ages between 60-80 years

\begin{tabular}{|c|c|c|c|c|c|c|c|}
\hline \multicolumn{8}{|c|}{$\mathrm{N}$ (MAF) } \\
\hline rs\# & Locus & Series & $A D$ & Control & OR & $95 \% \mathrm{Cl}$ & $p$-value \\
\hline & & All & $2,152(0.35)$ & $3,013(0.34)$ & 0.99 & $0.90-1.11$ & NS \\
\hline & & $J S$ & $544(0.37)$ & $634(0.33)$ & 1.24 & $1.03-1.49$ & 0.025 \\
\hline & & RS & $287(0.34)$ & $1,423(0.34)$ & 0.99 & $0.80-1.21$ & NS \\
\hline \multirow[t]{7}{*}{ rs156697 } & GSTO2 & AUT & $263(0.34)$ & $254(0.38)$ & 0.88 & $0.67-1.15$ & NS \\
\hline & & NCRAD & $531(0.34)$ & $119(0.45)$ & 0.58 & $0.41-0.82$ & 0.002 \\
\hline & & NW & $165(0.33)$ & $428(0.30)$ & 1.01 & $0.75-1.37$ & NS \\
\hline & & PS & $362(0.37)$ & $155(0.36)$ & 0.99 & $0.71-1.37$ & NS \\
\hline & & All & $2,148(0.32)$ & $3,011(0.31)$ & 1.00 & $0.90-1.11$ & NS \\
\hline & & JS & $544(0.33)$ & $644(0.29)$ & 1.16 & $0.96-1.40$ & 0.119 \\
\hline & & RS & $289(0.30)$ & $1,414(0.31)$ & 0.95 & $0.77-1.17$ & NS \\
\hline \multirow[t]{4}{*}{ rs4925 } & GSTO1 & AUT & $265(0.29)$ & $254(0.34)$ & 0.85 & $0.64-1.12$ & 0.248 \\
\hline & & NCRAD & $522(0.31)$ & $117(0.31)$ & 0.86 & $0.6-1.24$ & NS \\
\hline & & NW & $158(0.31)$ & $423(0.29)$ & 0.94 & $0.69-1.29$ & NS \\
\hline & & PS & $370(0.35)$ & $159(0.34)$ & 0.94 & $0.67-1.31$ & NS \\
\hline
\end{tabular}

Results of multivariate logistic regression analysis are shown for each SNP, each series individually and for the combined series. $\mathrm{N}=\mathrm{number}$ of subjects, MAF = minor allele frequency, OR = odds ratio; NS = not significant. 
Table 7 Association of GSTO locus SNPs with LOAD risk in the LOAD series all ages combined

\begin{tabular}{|c|c|c|c|c|c|c|c|}
\hline \multicolumn{8}{|c|}{$\underline{N}$ (MAF) } \\
\hline rs\# & Locus & Series & $A D$ & Control & OR & $95 \% \mathrm{Cl}$ & $p$-value \\
\hline & & All & $3,490(0.36)$ & $4,617(0.34)$ & 1.06 & $0.98-1.14$ & 0.177 \\
\hline & & JS & $853(0.37)$ & $953(0.33)$ & 1.19 & $1.03-1.38$ & 0.021 \\
\hline & & RS & $586(0.35)$ & $2,386(0.33)$ & 1.07 & $0.93-1.23$ & NS \\
\hline \multirow[t]{7}{*}{ rs156697 } & GSTO2 & AUT & $574(0.38)$ & $353(0.37)$ & 0.98 & $0.79-1.22$ & NS \\
\hline & & NCRAD & $677(0.35)$ & $205(0.39)$ & 0.78 & $0.60-1.02$ & 0.069 \\
\hline & & NW & $341(0.33)$ & $544(0.30)$ & 1.10 & $0.87-1.39$ & NS \\
\hline & & PS & $459(0.37)$ & $176(0.35)$ & 1.00 & $0.75-1.35$ & NS \\
\hline & & All & $3,489(0.32)$ & $4,606(0.31)$ & 1.03 & $0.95-1.12$ & NS \\
\hline & & JS & $850(0.32)$ & $965(0.30)$ & 1.12 & $0.96-1.31$ & 0.137 \\
\hline & & RS & $591(0.31)$ & $2,374(0.31)$ & 1.04 & $0.90-1.21$ & NS \\
\hline \multirow[t]{4}{*}{ rs4925 } & GSTO1 & AUT & $578(0.33)$ & $353(0.34)$ & 0.89 & $0.71-1.11$ & NS \\
\hline & & NCRAD & $671(0.31)$ & $197(0.29)$ & 1.01 & $0.76-1.34$ & NS \\
\hline & & NW & $331(0.31)$ & $537(0.29)$ & 1.03 & $0.81-1.32$ & NS \\
\hline & & PS & $468(0.35)$ & $180(0.34)$ & 0.93 & $0.69-1.26$ & NS \\
\hline
\end{tabular}

Results of multivariate logistic regression analysis are shown for each SNP, each series individually and for the combined series. $\mathrm{N}=$ number of subjects, MAF $=$ minor allele frequency, $\mathrm{OR}=$ odds ratio; $\mathrm{NS}=$ not significant.

cortex; and in both the AD and control autopsy subjects, although the effect size estimates appeared to be bigger for the ADs and the cerebellum. The minor alleles of both SNPs were associated with lower brain GSTO2 levels in all analyses, with an additive pattern of association (Figure 2).

Twenty other cisSNPs at the GSTO locus were tested for association with brain GSTO1 and GSTO2 levels in our eGWAS. Although rs156697 had the strongest association, many of the additional cisSNPs also showed significant association with brain GSTO2 (Additional File 1: Table S2, Additional File 2: Figure S1), but not GSTO1 (data not shown) levels. The strongest cisSNPs were in an LD block encompassing GSTO2 (Additional File 2: Figure S1.)

\section{Discovery of glutathione metabolism pathway in a brain gene expression GWAS}

In our brain eGWAS we identified 686 genes with cerebellar transcript levels that are significantly influenced by cisSNPs, which were submitted to pathway analysis [33] to discover molecular pathways that are significantly regulated in the brain. Glutathione metabolism was identified as one of the most significant pathways ( $p$ $=0.0035$ ), where six genes from this pathway out of the thirty that existed within our eGWAS had significant a.

Odds ratio meta-analysis plot [random effects]

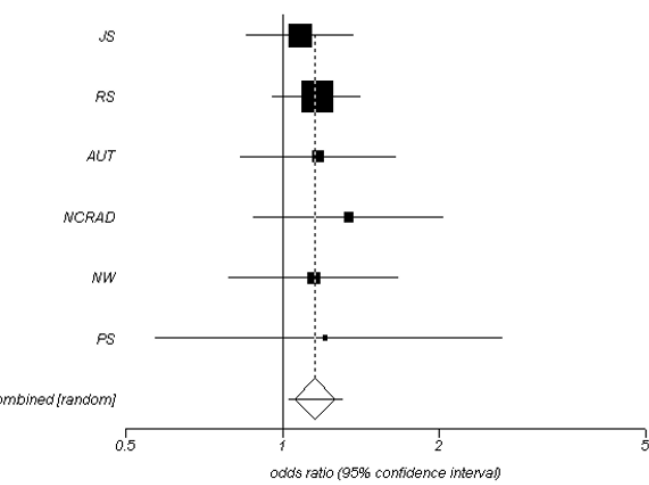

b.

Odds ratio meta-analysis plot [random effects]
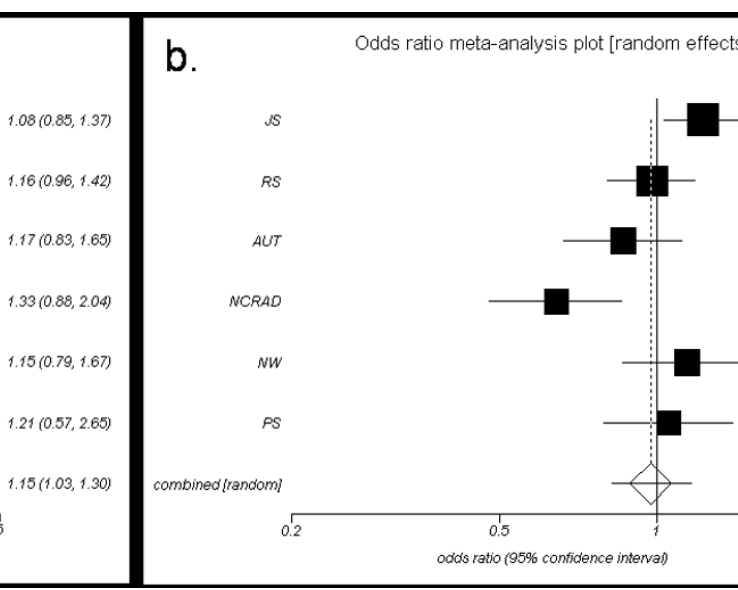

$1.23(1.03,1.46)$

$0.98(0.81,1.19)$

$0.86(0.66,1.12)$

$0.64(0.48,0.86)$

$1.14(0.86,1.51)$

$1.05(0.79,1.41)$

$0.98(0.82,1.17)$

Figure 1 Meta-analysis of rs156697 in LOAD: a) Older LOAD series with ages > 80 years; b) Younger LOAD series with ages between 60-80 years. Combined series $p$ value of association with LOAD risk is $p=0.018$ in the older and $p=0.79$ in the younger LOAD series. BreslowDay test for series heterogeneity $p$ value $=0.97$ in the older and $p=0.004$ in the younger series. 
Table 8 Association of GSTO locus SNPs with PD risk

\begin{tabular}{|c|c|c|c|c|c|c|c|}
\hline \multicolumn{8}{|c|}{$\underline{\mathrm{N}(\mathrm{MAF})}$} \\
\hline rs\# & Locus & Series & PD & Control & OR & $95 \% \mathrm{Cl}$ & $\mathrm{p}$-value \\
\hline & & PD-All & $661(0.35)$ & $702(0.36)$ & 0.94 & $0.80-1.11$ & NS \\
\hline \multirow[t]{3}{*}{ rs156697 } & GSTO1 & PD-SPO & $411(0.36)$ & $702(0.36)$ & 1.03 & $0.85-1.24$ & NS \\
\hline & & PD FAM & $250(0.31)$ & $702(0.36)$ & 0.83 & $0.66-1.05$ & 0.116 \\
\hline & & PD-All & $667(0.30)$ & $707(0.33)$ & 0.92 & 0.78-1.09 & NS \\
\hline \multirow[t]{2}{*}{ rs4925 } & GSTO1 & PD-SPO & $416(0.33)$ & 707 (0.33) & 1.03 & $0.85-1.25$ & NS \\
\hline & & PD FAM & $251(0.27)$ & $707(0.33)$ & 0.78 & $0.61-0.98$ & 0.034 \\
\hline
\end{tabular}

Results of multivariate logistic regression analysis are shown for each SNP, each series individually and for the combined series. $\mathrm{N}=$ number of subjects, $\mathrm{MAF}=$ minor allele frequency, OR = odds ratio; NS = not significant.

cisSNPs that influence both the cerebellar and temporal cortex levels of these genes (Additional Files 3: Figure $\mathrm{S} 2 \mathrm{a}$ and 4: Figure S2b). Five of the significant genes are enzymes that directly catalyze the binding of reduced glutathione to substrates (GSTO2, GSTT1, GSTT2, GSTM3, GSTM5) and GCTG is involved in amino acid metabolism, including glutamate (Additional File 1).

\section{Discussion}

GSTO1 and GSTO2, which are evolutionarily conserved genes[14], previously implicated in $\mathrm{AD}[5,6,9,11]$ and $\mathrm{PD}$ $[5,16]$, have diverse attributed functions including antioxidant activity via generation of ascorbate (Vitamin C) [14,34,35]; biotransformation of inorganic arsenic[14,34]; modulation of ryanodine receptors and thus calcium release and apoptosis[36]; and post-translational processing of the pro-inflammatory cytokine, IL-1 $\beta[15]$. Given their functions which are relevant for the pathophysiology of neurodegenerative diseases and their location in linkage regions for $\mathrm{AD}[11-13]$ and $\mathrm{PD}[13]$, GSTO locus variants have previously been studied for their association with risk and age-at-onset of $\mathrm{AD}$ and $\mathrm{PD}$ with mixed results[5,6,9,11,14,16-18].

In this study, we assessed two coding polymorphisms, rs4925 (Ala140Asp) in GSTO1 and rs156697 (Asn142Asp) in GSTO2 in a large LOAD series of $>$ 8,000 subjects, $\sim 3,000$ of whom were older ( $>80$ years) and in a PD series of $>1,300$ subjects including both

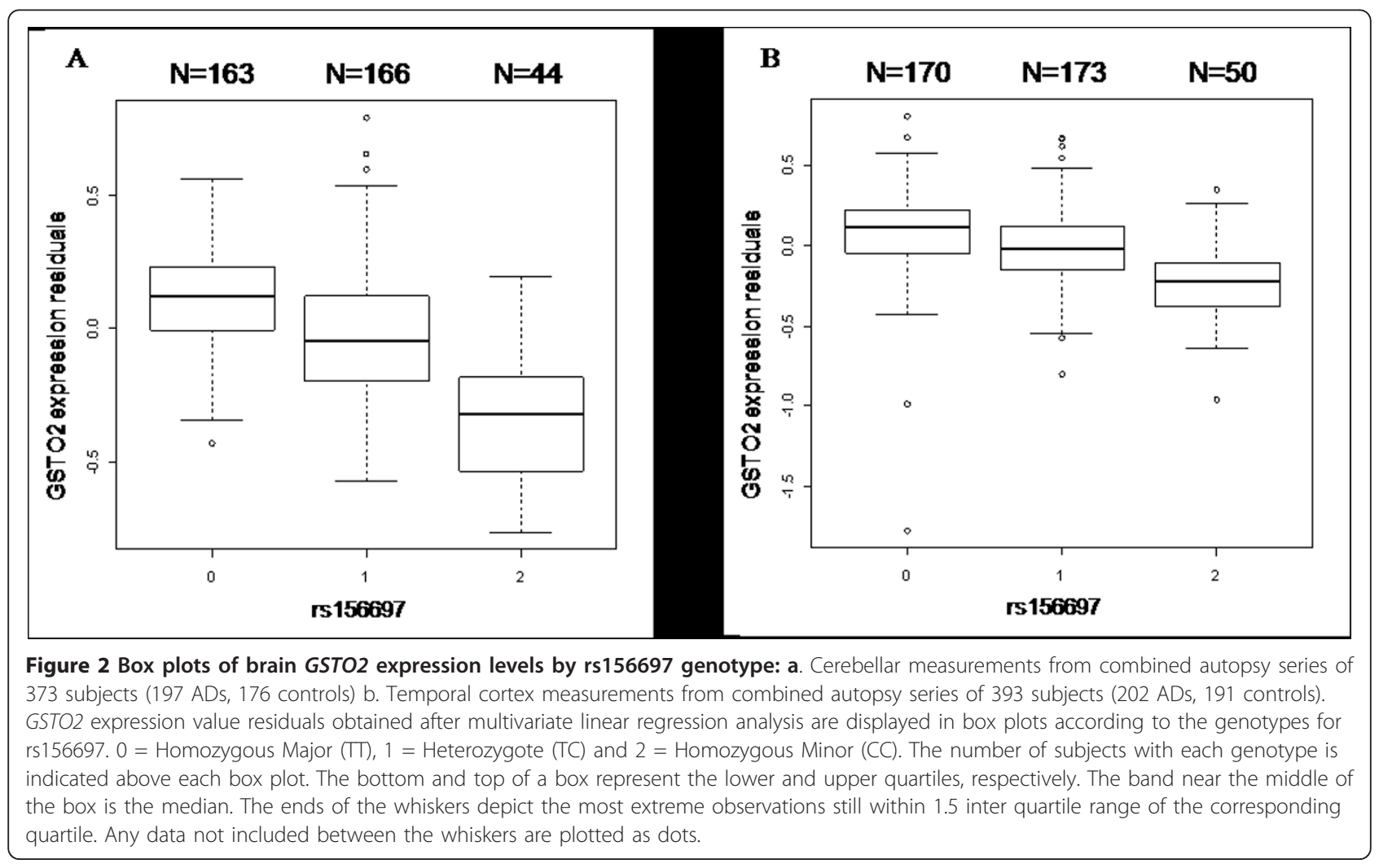


Table 9 Association of GSTO locus SNP rs156697 with brain GSTO2 expression levels

\begin{tabular}{ccccc}
\hline Tissue & Diagnosis & N & Beta & P-value \\
\hline \multirow{2}{*}{ Cer } & All & 373 & -0.200 & $1.90 \mathrm{E}-27$ \\
\cline { 2 - 5 } & AD & 197 & -0.225 & $1.12 \mathrm{E}-17$ \\
\cline { 2 - 5 } & Con & 176 & -0.173 & $1.15 \mathrm{E}-10$ \\
\hline \multirow{2}{*}{ Tx } & All & 393 & -0.146 & $1.20 \mathrm{E}-14$ \\
\cline { 2 - 5 } & AD & 202 & -0.166 & $2.50 \mathrm{E}-10$ \\
\cline { 2 - 5 } & Con & 191 & -0.119 & $3.30 \mathrm{E}-05$ \\
\hline
\end{tabular}

Results of multivariate linear regression analysis testing association of rs156697 with cerebellar (Cer) and temporal cortex (Tx) levels of GSTO2 in the autopsied subjects with AD pathology, those without (Con), and the combined (All) group. $\mathrm{N}=$ number of subjects. Beta coefficient and $\mathrm{p}$ value of association between the transcript levels and the SNP are shown for each analyzed series.

familial and sporadic cases. We found significant LOAD risk association for the minor allele of rs156697 in older subjects and a suggestive trend for delayed age-at-diagnosis. These results are consistent with the original[5] and some of the follow-up reports on this locus[9,11], and suggest that the reported delay in age-at-onset is likely to be due to an increased risk conferred in older subjects. Given the age-dependent decline in key glutathione metabolism components and their role in mitigating oxidative stress[32], the postulate that risky GSTO variants lead to increased risk in older LOADs due to accumulation of oxidative damage with increasing age, is a plausible scenario. It should be emphasized that our study utilized age-at-diagnosis as a surrogate for age-at-onset and unrelated case-controls, rather than family-based series. These differences could underlie the marginal age association in our study, in comparison to the original study[5].

Given the tight LD ( $\mathrm{r} 2=0.73, \mathrm{D}^{\prime}=0.94$ in HapMap3) [37] between the two coding SNPs tested for AD and PD risk association in this study, we did not correct for multiple testing. If corrected, the $\mathrm{AD}$ association in the older ADs would no longer be significant $(p=0.076)$.

Table 10 Association of GSTO locus SNP rs4925 with brain GSTO2 expression levels

\begin{tabular}{ccccc}
\hline Tissue & Diagnosis & $\mathbf{N}$ & Beta & P-value \\
\hline \multirow{2}{*}{ Cer } & All & 371 & -0.175 & $6.88 \mathrm{E}-19$ \\
\cline { 2 - 5 } & AD & 196 & -0.203 & $2.23 \mathrm{E}-12$ \\
\cline { 2 - 5 } & Con & 175 & -0.149 & $4.91 \mathrm{E}-08$ \\
\hline \multirow{2}{*}{ Tx } & All & 392 & -0.132 & $4.70 \mathrm{E}-11$ \\
\cline { 2 - 5 } & AD & 201 & -0.167 & $3.93 \mathrm{E}-09$ \\
\cline { 2 - 5 } & Con & 191 & -0.089 & $2.30 \mathrm{E}-03$ \\
\hline
\end{tabular}

Results of multivariate linear regression analysis testing association of rs4925 with cerebellar (Cer) and temporal cortex (Tx) levels of GSTO2 in the autopsied subjects with AD pathology, those without (Con), and the combined (All) group. $\mathrm{N}=$ number of subjects. Beta coefficient and $\mathrm{p}$ value of association between the transcript levels and the SNP are shown for each analyzed series.
Furthermore, GSTO locus variants were not reported to have significant or suggestive association with AD risk in the recent, large GWAS[26-28]. Although, these findings could collectively suggest that the AD risk association in our study is a false positive, there are alternative explanations: First, the effect conferred by GSTO2 rs156697 is age-specific based on our results, and others [5]. Additionally, unlike the older series in our study, the younger LOAD series had significantly heterogeneous results for the rs156697 SNP. Thus, the large LOAD GWAS need to be re-analyzed focusing on the different age groups and also for age-at-onset or diagnosis association. Second, the effect of the GSTO2 variant is likely modest for LOAD risk, despite strong effects on brain gene expression. Third, although GSTO2 rs156697 has the strongest effect on brain expression of this gene in that locus, it may still not be the functional variant, thus leading to weak or heterogeneous effects on LOAD risk. Our results in LOAD risk and brain gene expression provide support for functional variant discovery efforts in the GSTO2 region and screening of such variants for their effects in transcriptional assays.

There was no significant association of GSTO SNPs with disease risk in the combined PD series. This may not be surprising given the difference in sample size and therefore power between the LOAD and PD series. Whereas our older LOAD series (1,338 LOAD vs. 1,604 controls) have $\sim 61 \%$ power to detect the effect of the GSTO2 rs156697 SNP (OR = 1.14), the combined PD series (661 PDs vs. 702 controls) tested for this SNP, has $\sim 32 \%$ power to detect this effect at $\alpha=0.05$. There was, however, association with decreased risk in the familial PD cases for the GSTO1 rs4925 minor allele. Although consistent with one other study in PD[16], this finding requires further replication. It is intriguing to note that this variant also conferred a protective effect in the LEAPS-PD GWAS, which assessed PD sibpairs in its first stage[38,39]. The opposite direction of association in the familial PDs (and some of the younger LOAD series) vs. the older LOAD series could have several explanations including the tested SNPs not being functional themselves but marking different functional variants of opposing effects; heterogeneity due to different gene-gene or gene-environment interactions in different groups; and false positivity in some of the tested series.

Although both GSTO SNPs are in coding regions, they do not lead to any change in the enzymatic activities of GSTO1[34,35] or GSTO2[34]. While their effects on LOAD and PD could be due to other, untested alterations in protein function, another potential mechanism of action is influencing levels of gene expression. Indeed, both SNPs had highly significant effects on brain gene expression levels of GSTO2, but not GSTO1. Amongst 
the 22 cisSNPs tested for association with GSTO levels in our brain eGWAS, rs156697 had the strongest effect, where the risky minor allele was associated with lower brain GSTO2 levels. These results strongly suggest that the risk conferred by the GSTO locus is most likely due to variants which influence GSTO2 levels in the brain. These findings are biologically compatible with the very high antioxidant function of GSTO2, where its dehydroascorbate reductase activity was found to be $70-100 \%$ greater than that of GSTO1[34].

Brain expression levels of other key enzymes of glutathione metabolism are also significantly influenced by genetic variants, as was identified from pathway analysis of our significant brain eGWAS results. Given our findings with GSTO2 and other studies implicating glutathione metabolism genes in neurodegenerative diseases[8,10,32], it will be important to analyze these additional glutathione metabolism genes with high brain regulation, for variants that influence risk of $\mathrm{AD}$ and other neurodegenerative diseases.

In summary, our results support GSTO2 as a risk gene for older LOAD subjects, where risky genotypes reduce brain levels of this gene, which likely leads to accumulation of oxidative damage worsening with increasing age. These findings have implications for disease mechanism, as well as the search for genetic risk variants in AD and other neurodegenerative diseases. First, it will be important to analyze the existing large LOAD and PD risk GWAS by different age-strata and also using age-at-onset as the outcome, where available. Second, GSTO2 should be sequenced for variants that may influence gene expression and thereby disease risk. Third, association with expression levels provides a unique opportunity to identify the actual disease gene at the linkage or association locus. Fourth, individual or combined assessment of glutathione pathway genes that are regulated in the brain, may uncover additional neurodegenerative risk variants. Further establishment of GSTO2 and other glutathione metabolism genes in AD and PD awaits discovery and mechanistic studies of functional genetic variants.

\section{Methods}

\section{Subjects and samples} $\angle O A D$ and $P D D N A$ samples

Unrelated subjects from six independent LOAD casecontrol series, consisting of Caucasians with an age-atdiagnosis (LOAD), evaluation (elderly controls) or death (autopsy series) $\geq 60$ years, were utilized in this study (3,561 LOAD vs. 4,683 controls; Table 1 Table 2 and Table 3). Subjects with younger (60-80) and older (> 80) ages were assessed both separately and jointly, as per our prior reports[40-42] and given the age-specific effects observed for many LOAD risk variants, including APOE[43]. Four case-control series were comprised of
Caucasian subjects collected in the United States, with three series collected at Mayo Clinic in Jacksonville, Florida (JS: 864 LOADs, 972 controls), Rochester, Minnesota, (RS: 597 LOADs, 2,406 controls) and an autopsy-confirmed series from the Brain Bank at Mayo Clinic Florida (AUT: 581 LOADs, 360 controls). The fourth Caucasian-American series was from the National Cell Repository for Alzheimer's Disease (NCRAD: 695 LOADs, 208 controls). These series were previously described in detail[40]. Two additional Caucasian series were from Poland[44] (PS: 479 LOADs, 186 controls) and Norway[45] (NW: 345 LOADs, 551 controls) were also included in this study. All clinical LOAD subjects had a diagnosis of probable or possible AD and all autopsied LOAD subjects of definite AD made according to NINCDS-ADRDA criteria[46]. All controls from the clinical Caucasian-American series had a clinical dementia rating score of 0 . All autopsied LOAD brains had Braak scores of $\geq 4.0$. Brains employed as controls had Braak scores of $\leq 2.5$ but often had pathologies unrelated to $\mathrm{AD}$.

We utilized age 80 as the arbitrary cutoff to define the older vs. younger LOAD series. This decision is partly based on the knowledge that the strongest genetic factor conferring LOAD risk, $A P O E \& 4$ has age-specific effects with highest effect sizes in younger ages (60-75)[47] (reviewed in [19]). Age-specific LOAD risk association has also been demonstrated for other genetic factors both by others $[48,49]$ and by our group [50]. These results suggest that older vs. younger LOAD subjects may be heterogeneous and harbor different genetic risk factors. Consequently, we have divided our LOAD casecontrol series into older vs. younger age groups using the 80 year cutoff and analyze these series both separately and jointly in all of our studies assessing LOAD genetic risk, including the Mayo LOAD GWAS which was focused on the 60-80 year group[51].

Caucasian-American, unrelated PD patients and controls (PD: 678 PDs, 712 controls) were recruited and diagnosed as described[52,53], by a neurologist according to published criteria[54]. Control subjects lacked any history suggestive of parkinsonism. PDs with family history of parkinsonism (familial, PD FAM) and those without (sporadic, PD-SPO) were analyzed both separately and jointly. All DNA samples were isolated from peripheral blood, with the exception of samples in the autopsy series where DNA was isolated from donated brain tissue, as described in previous publications $[40,44,45,52]$. This study was approved by the appropriate institutional review board and appropriate informed consent was obtained from all participants.

\section{RNA samples}

Brain RNA for gene expression studies was obtained from the Mayo Clinic Autopsy (AUT) series, described 
above. These subjects were part of a larger expression GWAS (eGWAS) (in-press Neurology and PloSGenetics). AUT subjects with an age-at-death of 60-80 years were included in the Mayo LOAD GWAS[51]. RNA was extracted from the frozen cerebellum and temporal cortex samples of these autopsied subjects, where available, using the $\mathrm{AB}$ (Applied Biosystems) RNA was extracted from the frozen cerebellum and temporal cortex samples of these autopsied subjects, where available, using the Ambion RNAqueous kit according to the manufacturer's instructions. The quantity and quality of the RNA samples were determined by the Agilent 2100 Bioanalyzer using the Agilent RNA 6000 Nano Chip. In total, 399 temporal cortex (202 LOADs, 197 Controls) and 374 cerebellar samples (197 LOADs, 177 Controls) were assessed.

\section{SNP genotyping}

This study initially focused on four known coding variants from dbSNP within GSTO1 (rs4925, rs11509438) and GSTO2 (rs156697, rs34400162). We determined that rs11509438 was below the required minor allele frequency (MAF) cutoff of $5 \%(\mathrm{MAF}=3.3 \%)$ and rs34400162 was monomorphic in our series. We therefore focused on rs4925 and r156697 in all downstream analyses. Taqman (Applied Biosystems) was used to genotype rs4925 and rs155697 in all case-control series.

The genotypes for the eGWAS were obtained as part of the Mayo LOAD GWAS using Illumina (San Diego, CA) HumanHap300-Duo Genotyping BeadChips, and were analyzed with an Illumina BeadLab Station (Illumina, San Diego, CA), followed by quality control (QC), as previously described[51].

\section{Expression measurements}

Transcript levels were measured using the Whole Genome DASL assay (Illumina, San Diego, CA). The RNA samples were randomized across the chips and plates using a stratified approach to ensure balance with respect to diagnosis, age, gender, RINs (RNA integrity numbers) and $A P O E$ genotype. Replicate samples were utilized for QC. Raw probe level mRNA expression data were exported from GenomeStudio software (Illumina Inc.) for preprocessing with background correction, variance stabilizing transformation, quantile normalization and probe filtering using the lumi package of BioConductor $[55,56]$.

\section{Statistical analysis}

\section{Disease-risk association analysis}

SNPs rs4925 and rs156697 were assessed for association with LOAD by multivariate logistic regression analysis using an allelic dosage model, adjusted for the following covariates: $A P O E \& 4$ dosage $(0,1,2)$, age at diagnosis/ evaluation/death, and gender. Analysis was executed for each of the six individual case control series and for the series combined, with a series covariate included in the model. All analyses were conducted separately on subjects of ages 60-80 years and those $>80$ years, separately, and jointly.

Analysis for PD risk was done in a similar fashion. The PDs were classified as familial vs. sporadic based on the presence of family history of parkinsonism, in this cohort. We have therefore assessed the familial and sporadic PDs against the common PD control group both separately and jointly.

Meta analysis was also performed for rs4925 and rs156997 association with LOAD risk using the DerSimonian-Laird random effects model[57]. The younger $(60-80)$ and older (> 80) age groups were analyzed separately, in addition to combined ages. Breslow-Day test for non-compatibility was used to test for series heterogeneity. Test statistics are reported for each series as well as the pooled test statistics from the random effects model.

\section{Age-at-diagnosis association analysis}

We employed age-at-diagnosis or death as the surrogate quantitative variable for age-at-onset in our LOAD subjects (3,561 LOADs). An additive model was assumed for the GSTO locus SNPs, with the minor allele dosage $(0,1,2)$ as the independent variable, and APOE $\varepsilon 4$ dosage $(0,1,2)$, and gender as covariates. Analysis was executed for the LOADs both individually for the six series and with all series combined, where a series covariate was included in the model.

PD age-at-diagnosis analysis was done similarly, for the familial and sporadic PDs both individually and jointly. Both the disease risk and age-at-diagnosis associations for the two GSTO SNPs were conducted in StatsDirect (v.2.5.8).

\section{Gene expression level association analysis}

All GSTO1 and GSTO2 trancript measurements and GSTO locus cisSNP/transcript associations were conducted as part of our brain eGWAS[58]. Pathway analysis described below was also conducted using the cisSNP/transcript association results from this eGWAS. GSTO locus SNPs rs4925 and rs156697 were tested for association with brain levels of GSTO1 and GSTO2 transcripts measured in the cerebellum and temporal cortex of autopsied subjects as part of our eGWAS. Preprocessed probe transcript levels (GSTO1 = ILMN_2227573 and GSTO2 = ILMN_1740234) were used as the quantitative traits and the analyses were conducted as described (in-press Neurology[58], PLoS Genetics). An additive model was assumed, with the minor allele dosage $(0,1,2)$ as the independent variable, and APOE $\varepsilon 4$ dosage $(0,1,2)$, age-at-death, gender, PCR plate, RIN, adjusted RIN2 (defined as (RIN-RINmean)2) as 
covariates. The cerebellar and temporal cortex results were analyzed separately. The autopsied LOADs and controls without AD pathology were analyzed both separately and jointly for rs4925 and rs156697, with the joint analysis including diagnosis as an additional covariate. Linear regression analysis to test for SNP/transcript associations were done with PLINK[59]. Box plots depicting transcript levels by SNP genotype were generated in R, for the residuals of the cerebellar and temporal cortex associations from the multivariate linear regression analysis described above.

Our brain eGWAS assessed association of brain transcript levels with their nearby cis SNPs described as those residing within the gene or its $\pm 100 \mathrm{~kb}$ flanking region. We determined that there were 20 additional cisSNPs tested for GSTO1 and GSTO2 in our eGWAS. The brain transcript level associations with these 20 cisSNPs were also assessed using the same analytical approach.

\section{Linkage disequilibrium analysis}

Linkage disequilibrium for the 20 GSTO locus cisSNPs, rs4925 and rs156697 was evaluated using the HapMap Caucasian (CEU) data[60] and assessed in HaploView version 4.1[61] with the solid spine algorithm.

\section{Pathway analysis}

In our brain eGWAS, we measured expression levels of 24,526 transcripts in 773 brain samples from the cerebellum and temporal cortex of autopsied subjects with Alzheimer's disease (AD, cerebellar $n=197$, temporal cortex $n=202$ ) and with other brain pathologies (control, cerebellar $\mathrm{n}=177$, temporal cortex $\mathrm{n}=197$ ) (inpress, PLoS Genetics). Association studies were carried out for the transcripts that could be detected in brain tissue, which is $\sim 70 \%$ of all tested transcripts and for the 213,528 cisSNPs which reside within $\pm 100 \mathrm{~kb}$ of the genomic region of the transcript. We identified 686 genes with cerebellar transcript levels that are significantly influenced by cisSNPs in both the AD and control samples. Importantly, 625 of these genes could be tested in the temporal cortex, of which 471 were also significant for the transcript associations in this other brain region.

To discover the molecular pathways which harbor the top genes with significant cisSNP associations, we performed pathway analysis using MetaCore[33]. The total number of tested genes and the number of significant genes that belong to a MetaCore pathway were used to determine the molecular pathways that are significantly enriched for genes influenced by cisSNPs in the brain. Out of 11,897 tested genes with eGWAS data, 3,316 belong to at least one MetaCore pathway. Out of 686 genes with significant cerebellar transcript/cisSNP associations, 188 belong to at least one MetaCore pathway. Pathways with less than five tested genes were excluded from analysis. Fisher $2 \times 2$ test with mid-p value was calculated in $\mathrm{R}$ to determine significance of enrichment.

\section{Additional material}

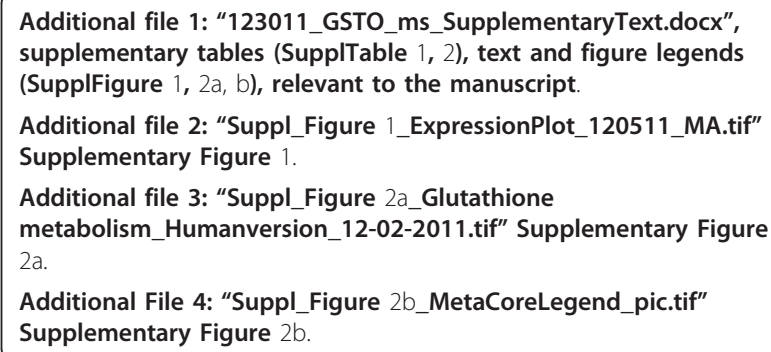

\section{Acknowledgements}

Support for this research was provided by the National Institutes of Health grants: National Institute on Aging (R01 032990 to NET and R01 AG018023 to NRG-R and SGY); Mayo Alzheimer's Disease Research Center: (P50 AG016574 to RCP, DWD, NRG-R, SGY, and NET); Mayo Alzheimer's Disease Patient Registry: (U01 AG006576 to RCP); National Institute on Aging (AG025711, AG017216, AG003949 to DWD). This project was also generously supported by the Robert and Clarice Smith and Abigail Van Buren Alzheimer's Disease Research Program (to RCP, DWD, NRG-R, and SGY), and by the Palumbo Professorship in Alzheimer's Disease Research (to SGY). N.E. $\mathrm{T}$. is the recipient of National Institutes of Health (KL2 RR024151), and Siragusa Foundation grants. RJU and ZKW are partially supported by the NIH/NINDS P50 NS072187-01 S2 and NS057567, and Mayo Clinic Florida (MCF) Research Committee CR program. ZKW is also partially supported by NIH/NINDS 1RC2NS070276 and Dystonia Medical Research Foundation.

\section{Author details}

${ }^{1}$ Mayo Clinic Florida, Department of Neuroscience, Jacksonville, FL, USA. ${ }^{2}$ Mayo Clinic Minnesota, Department of Biostatistics, Rochester, MN, USA. ${ }^{3}$ Mayo Clinic Florida, Biostatistics Unit, Jacksonville, FL, USA. ${ }^{4}$ Mayo Clinic Minnesota, Gene Expression Core, Advanced Genome Technology Center Rochester, MN, USA. ${ }^{5}$ Department of Neurology, St.Olav's Hospital, Edvard Griegs Gate 8, 7006 Trondheim, Norway. ${ }^{6}$ Department of Neuroscience, Norwegian University of Science and Technology, NTNU, 7491 Trondheim, Norway. ${ }^{7}$ Department of Neurodegenerative Disorders, Medical Research Centre, Polish Academy of Sciences, Warsaw, Poland. ${ }^{8}$ Mayo Clinic Florida, Department of Neurology, Jacksonville, FL, USA. ${ }^{9}$ Mayo Clinic Minnesota, Department of Neurology, Rochester, MN, USA.

\section{Authors' contributions}

MA carried out SNP genotyping assays, executed the disease risk and age at onset statistical analysis and helped to draft the manuscript. FZ participated in the organization and design of the gene expression study. HSC, CSY and AAN significantly contributed to the analysis of the gene expression data. RM participated in the collection of the gene expression data and carried out SNP genotyping assays. JEC and VSP significantly contributed to the design of the gene expression study and statistical analysis. MMC led the design, collection and analysis of SNP genotyping data used for the gene expression study. CNR and RP carried out SNP genotyping assays. TN, LM, KGM, GB and AIO provided technical expertise in the preparation, organization and maintenance of the RNA and DNA samples. SM, SM and CG participated in the analysis of the gene expression data. DS and FR participated in the collection of gene expression data. CPK and JJ supervised the collection of gene expression data. SBS, JOA, MB, RJU, ZKW, OAR, RCP, NRG and DWD collected and provided the case-control samples used in these studies. SGY significantly contributed to the conception and organization of the study. NET conceived of the study, and participated in its design and coordination and helped to draft the manuscript. All authors read and approved the final manuscript. 


\section{Competing interests}

N. Graff-Radford, M.D. has served as a consultant to Codman and received grant support from Elan Pharmaceutical Research, Pfizer Pharmaceuticals, Medivation, and Forrest. R.C. Petersen, M.D., Ph.D. has been a consultant to GE Healthcare and Elan Pharmaceuticals, has served on a data safety monitoring board in a clinical trial sponsored by Elan Pharmaceuticals, and a safety monitoring board for Wyeth Pharmaceuticals.

Received: 3 January 2012 Accepted: 11 April 2012

Published: 11 April 2012

\section{References}

1. Gawryluk JW, Wang JF, Andreazza AC, Shao L, Yatham LN, Young LT: Prefrontal cortex glutathione S-transferase levels in patients with bipolar disorder, major depression and schizophrenia. Int J Neuropsychopharmacol 2011, 14:1069-1074.

2. Andreazza AC, Kapczinski F: Kauer-Sant'Anna M, Walz JC, Bond DJ, Goncalves CA, Young LT, Yatham LN: 3-Nitrotyrosine and glutathione antioxidant system in patients in the early and late stages of bipolar disorder. J Psychiatry Neurosci 2009, 34:263-271.

3. Gravina P, Spoletini I, Masini S, Valentini A, Vanni D, Paladini E, Bossu P, Caltagirone C, Federici G, Spalletta G, Bernardini S: Genetic polymorphisms of glutathione S-transferases GSTM1, GSTT1, GSTP1 and GSTA1 as risk factors for schizophrenia. Psychiatry Res 2011, 187:454-456.

4. Rodriguez-Santiago B, Brunet A, Sobrino B, Serra-Juhe C, Flores R, Armengol L, Vilella E, Gabau E, Guitart M, Guillamat R, et al: Association of common copy number variants at the glutathione S-transferase genes and rare novel genomic changes with schizophrenia. Mol Psychiatry 2010, 15:1023-1033.

5. Li YJ, Oliveira SA, Xu P, Martin ER, Stenger JE, Scherzer CR, Hauser MA, Scott WK, Small GW, Nance MA, et al: Glutathione S-transferase omega-1 modifies age-at-onset of Alzheimer disease and Parkinson disease. Hum Mol Genet 2003, 12:3259-3267.

6. Kolsch $H$, Linnebank M, Lutjohann $D$, Jessen $F$, Wullner $U$, Harbrecht $U$, Thelen KM, Kreis M, Hentschel F, Schulz A, et al: Polymorphisms in glutathione S-transferase omega-1 and AD, vascular dementia, and stroke. Neurology 2004, 63:2255-2260.

7. Li YJ, Scott WK, Zhang L, Lin PI, Oliveira SA, Skelly T, Doraiswamy MP, Welsh-Bohmer KA, Martin ER, Haines JL, et al: Revealing the role of glutathione S-transferase omega in age-at-onset of Alzheimer and Parkinson diseases. Neurobiol Aging 2006, 27:1087-1093.

8. van de Giessen E, Fogh I, Gopinath S, Smith B, Hu X, Powell J, Andersen P, Nicholson G: Al Chalabi A, Shaw CE: Association study on glutathione Stransferase omega 1 and 2 and familial ALS. Amyotroph Lateral Scler 2008, 9:81-84.

9. Capurso C, Panza F, Seripa D, Frisardi V, Imbimbo BP, Verdile G, Vendemiale G, Pilotto A, Solfrizzi V: Polymorphisms in glutathione Stransferase omega-1 gene and increased risk of sporadic Alzheimer disease. Rejuvenation Res 2010, 13:645-652.

10. Maes OC, Schipper HM, Chong G, Chertkow HM, Wang E: A GSTM3 polymorphism associated with an etiopathogenetic mechanism in Alzheimer disease. Neurobiol Aging 2010, 31:34-45.

11. Lee JH, Mayeux R, Mayo D, Mo J, Santana V, Williamson J, Flaquer A Ciappa A, Rondon H, Estevez P, et al: Fine mapping of $10 \mathrm{q}$ and $18 \mathrm{q}$ for familial Alzheimer's disease in Caribbean Hispanics. Mol Psychiatry 2004, 9:1042-1051.

12. Blacker D, Bertram L, Saunders AJ, Moscarillo TJ, Albert MS, Wiener H, Perry RT, Collins JS, Harrell LE, Go RC, et al: Results of a high-resolution genome screen of 437 Alzheimer's Disease families. Hum Mol Genet 2003, 12:23-32.

13. Li YJ, Scott WK, Hedges DJ, Zhang F, Gaskell PC, Nance MA, Watts RL, Hubble JP, Koller WC, Pahwa R, et al: Age at onset in two common neurodegenerative diseases is genetically controlled. Am J Hum Genet 2002, 70:985-993.

14. Whitbread AK, Masoumi A, Tetlow N, Schmuck E, Coggan M, Board PG: Characterization of the omega class of glutathione transferases. Methods Enzymol 2005, 401:78-99.

15. Laliberte RE, Perregaux DG, Hoth LR, Rosner PJ, Jordan CK, Peese KM, Eggler JF, Dombroski MA, Geoghegan KF, Gabel CA: Glutathione stransferase omega 1-1 is a target of cytokine release inhibitory drugs and may be responsible for their effect on interleukin-1 beta posttranslational processing. J Biol Chem 2003, 278:16567-16578.

16. Wahner $A D$, Glatt CE, Bronstein JM, Ritz B: Glutathione S-transferase mu, omega, pi, and theta class variants and smoking in Parkinson's disease. Neurosci Lett 2007, 413:274-278.

17. Nishimura M, Sakamoto T, Kaji R, Kawakami H: Influence of polymorphisms in the genes for cytokines and glutathione S-transferase omega on sporadic Alzheimer's disease. Neurosci Lett 2004, 368:140-143.

18. Ozturk A, Desai PP, Minster RL, Dekosky ST, Kamboh MI: Three SNPs in the GSTO1, GSTO2 and PRSS11 genes on chromosome 10 are not associated with age-at-onset of Alzheimer's disease. Neurobiol Aging 2005, 26:1161-1165.

19. Ertekin-Taner N: Genetics of Alzheimer's disease: a centennial review. Neurol Clin 2007, 25:611-667.

20. Ertekin-Taner N: Genetics of Alzheimer disease in the pre- and postGWAS era. Alzheimers Res Ther 2010, 2:3.

21. Wider C, Wszolek ZK: Clinical genetics of Parkinson's disease and related disorders. Parkinsonism Relat Disord 2007, 13(Suppl 3):S229-S232.

22. Golub Y, Berg D, Calne DB, Pfeiffer RF, Uitti RJ, Stoessl AJ, Wszolek ZK, Farrer MJ, Mueller JC, Gasser T, Fuchs J: Genetic factors influencing age at onset in LRRK2-linked Parkinson disease. Parkinsonism Relat Disord 2009, 15:539-541.

23. Haugarvoll K, Wszolek ZK: Clinical features of LRRK2 parkinsonism. Parkinsonism Relat Disord 2009, 15(Suppl 3):S205-S208.

24. Harold D, Abraham R, Hollingworth P, Sims R, Gerrish A, Hamshere ML, Pahwa JS, Moskvina V, Dowzell K, Williams A, et al: Genome-wide association study identifies variants at CLU and PICALM associated with Alzheimer's disease. Nat Genet 2009, 41:1088-1093.

25. Lambert JC, Heath S, Even G, Campion D, Sleegers K, Hiltunen M, Combarros O, Zelenika D, Bullido MJ, Tavernier B, et al: Genome-wide association study identifies variants at CLU and CR1 associated with Alzheimer's disease. Nat Genet 2009, 41:1094-1099.

26. Seshadri S, Fitzpatrick AL, Ikram MA, DeStefano AL, Gudnason V, Boada M, Bis JC, Smith AV, Carassquillo MM, Lambert JC, et al: Genome-wide analysis of genetic loci associated with Alzheimer disease. JAMA 2010, 303:1832-1840.

27. Naj AC, Jun G, Beecham GW, Wang LS, Vardarajan BN, Buros J, Gallins PJ, Buxbaum JD, Jarvik GP, Crane PK, et al: Common variants at MS4A4/ MS4A6E, CD2AP, CD33 and EPHA1 are associated with late-onset Alzheimer's disease. Nat Genet 2011, 43:436-441.

28. Hollingworth P, Harold D, Sims R, Gerrish A, Lambert JC, Carrasquillo MM, Abraham R, Hamshere ML, Pahwa JS, Moskvina V, et al: Common variants at ABCA7, MS4A6A/MS4A4E, EPHA1, CD33 and CD2AP are associated with Alzheimer's disease. Nat Genet 2011, 43:429-435.

29. Satake W, Nakabayashi Y, Mizuta I, Hirota Y, Ito C, Kubo M, Kawaguchi T, Tsunoda T, Watanabe M, Takeda A, et al: Genome-wide association study identifies common variants at four loci as genetic risk factors for Parkinson's disease. Nat Genet 2009, 41:1303-1307.

30. Simon-Sanchez J, Schulte C, Bras JM, Sharma M, Gibbs JR, Berg D, PaisanRuiz C, Lichtner P, Scholz SW, Hernandez DG, et al: Genome-wide association study reveals genetic risk underlying Parkinson's disease. Nat Genet 2009, 41:1308-1312.

31. Manolio TA, Collins FS, Cox NJ, Goldstein DB, Hindorff LA, Hunter DJ, McCarthy MI, Ramos EM, Cardon LR, Chakravarti A, et al: Finding the missing heritability of complex diseases. Nature 2009, 461:747-753.

32. Liu H, Wang $H$, Shenvi $S$, Hagen TM, Liu RM: Glutathione metabolism during aging and in Alzheimer disease. Ann N Y Acad Sci 2004, 1019:346-349

33. Ekins S, Nikolsky Y, Bugrim A, Kirillov E, Nikolskaya T: Pathway mapping tools for analysis of high content data. Methods Mol Biol 2007, 356:319-350.

34. Schmuck EM, Board PG, Whitbread AK, Tetlow N, Cavanaugh JA, Blackburn AC, Masoumi A: Characterization of the monomethylarsonate reductase and dehydroascorbate reductase activities of Omega class glutathione transferase variants: implications for arsenic metabolism and the age-at-onset of Alzheimer's and Parkinson's diseases. Pharmacogenet Genomics 2005, 15:493-501.

35. Whitbread AK, Tetlow N, Eyre HJ, Sutherland GR, Board PG Characterization of the human Omega class glutathione transferase genes and associated polymorphisms. Pharmacogenetics 2003, 13:131-144. 
36. Dulhunty A, Gage P, Curtis S, Chelvanayagam G, Board P: The glutathione transferase structural family includes a nuclear chloride channel and a ryanodine receptor calcium release channel modulator. J Biol Chem 2001, 276:3319-3323.

37. Johnson AD, Handsaker RE, Pulit SL, Nizzari MM, O'Donnell CJ, de Bakker PI: SNAP: a web-based tool for identification and annotation of proxy SNPS using HapMap. Bioinformatics 2008, 24:2938-2939.

38. Maraganore DM, de Andrade M, Lesnick TG, Strain KJ, Farrer MJ, Rocca WA, Pant PV, Frazer KA, Cox DR, Ballinger DG: High-resolution whole-genome association study of Parkinson disease. Am J Hum Genet 2005, 77:685-693.

39. Lill CM, Roehr JT, McQueen MB, Kavvoura F, Bagade S, Schjeide BMM, Schjeide L, Meissner E, Zauft U, Allen NC, et al: The PDGene Database. Alzheimer Research Forum., Available at: http://www.pdgene.org/. Accessed [03-04-2012].

40. Zou F, Carrasquillo MM, Pankratz VS, Belbin O, Morgan K, Allen M Wilcox SL, Ma L, Walker LP, Kouri N, et al: Gene expression levels as endophenotypes in genome-wide association studies of Alzheimer disease. Neurology 2010, 74:480-486.

41. Burgess JD, Pedraza O, Graff-Radford NR, Hirpa M, Zou F, Miles R, Nguyen T, Li M, Lucas JA, Ivnik RJ, et al: Association of common KIBRA variants with episodic memory and AD risk. Neurobiol Aging 2011, 32:557 e551-559.

42. Allen M, Cox C, Belbin O, Ma L, Bisceglio GD, Wilcox SL, Howell CC, Hunter TA, Culley O, Walker LP, et al: Association and heterogeneity at the GAPDH locus in Alzheimer's disease. Neurobiol Aging 2012, 33:203 e225-233.

43. Khachaturian AS, Corcoran CD, Mayer LS, Zandi PP, Breitner JC: Apolipoprotein E epsilon4 count affects age at onset of Alzheimer disease, but not lifetime susceptibility: The Cache County Study. Arch Gen Psychiatry 2004, 61:518-524.

44. Klimkowicz-Mrowiec A, Marona M, Wolkow P, Maruszak A, Styczynska M, Barcikowska M, Zekanowski C, Szczudlik A, Slowik A: Interleukin-1 gene -511 CT polymorphism and the risk of Alzheimer's disease in a Polish population. Dement Geriatr Cogn Disord 2009, 28:461-464

45. Sando SB, Melquist S, Cannon A, Hutton ML, Sletvold O, Saltvedt I, White LR, Lydersen S, Aasly JO: APOE epsilon 4 lowers age at onset and is a high risk factor for Alzheimer's disease; a case control study from central Norway. BMC Neurol 2008, 8:9.

46. McKhann G, Drachman D, Folstein M, Katzman R, Price D, Stadlan EM: Clinical diagnosis of Alzheimer's disease: report of the NINCDS-ADRDA Work Group under the auspices of Department of Health and Human Services Task Force on Alzheimer's Disease. Neurology 1984, 34:939-944.

47. Farrer LA, Cupples LA, Haines JL, Hyman B, Kukull WA, Mayeux R, Myers RH, Pericak-Vance MA, Risch N, van Duijn CM: Effects of age, sex, and ethnicity on the association between apolipoprotein $\mathrm{E}$ genotype and Alzheimer disease. A meta-analysis. APOE and Alzheimer Disease Meta Analysis Consortium. JAMA 1997, 278:1349-1356

48. Li Y, Nowotny P, Holmans P, Smemo S, Kauwe JS, Hinrichs AL, Tacey K, Doil L, van Luchene R, Garcia V, et al: Association of late-onset Alzheimer's disease with genetic variation in multiple members of the GAPD gene family. Proc Natl Acad Sci USA 2004, 101:15688-15693.

49. Lin PI, Martin ER, Bronson PG, Browning-Large C, Small GW, Schmechel DE, Welsh-Bohmer KA, Haines JL, Gilbert JR, Pericak-Vance MA: Exploring the association of glyceraldehyde-3-phosphate dehydrogenase gene and Alzheimer disease. Neurology 2006, 67:64-68.

50. Burgess JD, Pedraza O, Graff-Radford NR, Hirpa M, Zou F, Miles R, Nguyen T, Li M, Lucas JA, Ivnik RJ, et al: Association of common KIBRA variants with episodic memory and AD risk. Neurobiol Aging 2011, 557:e1-9.

51. Carrasquillo MM, Zou F, Pankratz VS, Wilcox SL, Ma L, Walker LP, Younkin SG, Younkin CS, Younkin LH, Bisceglio GD, et al: Genetic variation in PCDH11X is associated with susceptibility to late-onset Alzheimer's disease. Nat Genet 2009, 41:192-198.

52. Wider C, Vilarino-Guell C, Heckman MG, Jasinska-Myga B, Ortolaza-Soto Al, Diehl NN, Crook JE, Cobb SA, Bacon JA, Aasly JO, et al: SNCA, MAPT, and GSK3B in Parkinson disease: a gene-gene interaction study. Eur J Neurol 2011, 18:876-881.

53. Uitti RJ, Baba Y, Wszolek ZK, Putzke DJ: Defining the Parkinson's disease phenotype: initial symptoms and baseline characteristics in a clinical cohort. Parkinsonism Relat Disord 2005, 11:139-145.

54. Gelb DJ, Oliver E, Gilman S: Diagnostic criteria for Parkinson disease. Arch Neurol 1999, 56:33-39.
55. Du P, Kibbe WA, Lin SM: lumi: a pipeline for processing Illumina microarray. Bioinformatics 2008, 24:1547-1548.

56. Lin SM, Du P, Huber W, Kibbe WA: Model-based variance-stabilizing transformation for Illumina microarray data. Nucleic Acids Res 2008, 36 e11.

57. DerSimonian R, Laird N: Meta-analysis in clinical trials. Control Clin Trials 1986, 7:177-188.

58. Allen M, Zou F, Chai HS, Younkin CS, Crook J, Pankratz VS, Carrasquillo MM, Rowley CN, Nair AA, Middha S, et al: Novel late-onset Alzheimer's disease loci variants associate with brain gene expression. Neurology 2012.

59. Purcell $S$, Neale B, Todd-Brown $K$, Thomas L, Ferreira MA, Bender D, Maller J, Sklar P, de Bakker PI, Daly MJ, Sham PC: PLINK: a tool set for wholegenome association and population-based linkage analyses. Am J Hum Genet 2007, 81:559-575.

60. Frazer KA, Ballinger DG, Cox DR, Hinds DA, Stuve LL, Gibbs RA, Belmont JW, Boudreau A, Hardenbol P, Leal SM, et al: A second generation human haplotype map of over 3.1 million SNPs. Nature 2007, 449:851-861.

61. Barrett JC, Fry B, Maller J, Daly MJ: Haploview: analysis and visualization of LD and haplotype maps. Bioinformatics 2005, 21:263-265.

doi:10.1186/1750-1326-7-13

Cite this article as: Allen et al:: Glutathione S-transferase omega genes in Alzheimer and Parkinson disease risk, age-at-diagnosis and brain gene expression: an association study with mechanistic implications. Molecular Neurodegeneration 2012 7:13.

\section{Submit your next manuscript to BioMed Central and take full advantage of:}

- Convenient online submission

- Thorough peer review

- No space constraints or color figure charges

- Immediate publication on acceptance

- Inclusion in PubMed, CAS, Scopus and Google Scholar

- Research which is freely available for redistribution

Submit your manuscript at www.biomedcentral.com/submit
C) Biomed Central 